\title{
THE IMPACT OF TECHNOLOGY ON THE USE OF FOREST PRODUCTS
}

\author{
By E. S. FELLOWS ${ }^{1}$
}

When I was invited to speak on this topic, my mind turned first to those developments which have opened up new outlets for wood, but I soon realised that this alone would contribute little to the theme of this meeting. One could compile a list of technological accomplishments of the wood-based industries which would give the impression that their impact on the use of wood has been very favourable and that therefore all is well. But even this cursory survey may suggest that the total impact of technology on wood utilization is not reassuring, and that this is especially true for Canada.

Let us start by considering some of the main areas where technology affects markets for wood products for better or worse. First, there is the technology of those industries producing competitive goods - steel and aluminum, cement and gypsum, tinplate, and plastics in sheet, thread, or moulded forms-to mention only the most prominent.

Second, there are those advances in technology which bestow their blessings un many industries indiscriminately or which were developed by some secondary industry primarily to serve one or more other industries. Consider, for example, what the crawler-type tractor has meant to logging during the past 35 years. A more modern illustration is the development of synthetic resins as adhesives and protective coatings. Today electronic developments are revolutionizing processing in a host of industries, including those which most concern us. The chain saw is a fine instance of a product developed by manufacturing industry for the almost-exclusive use of an extractive one.

Third, there is the technology of design which is at least partly related to fads and fashions. To illustrate the resulting changes one might cite architectural styles and also the trend toward the displacement of re-usable articles by disposable ones-containers, handkerchiefs, and now, we hear, even clothing.

Fourth, there are the innovations within the forest-based industries themselves. Here, as in most other industries, the changes fall into four or five categories. The commonest are those refinements which do not necessarily have any bearing on the end-product other than to reduce its cost. Witness the advent of huge pulpwood-harvesting machines, improvements in sawmill equipment, larger and better presses for the production of panel boards of all kinds, and all sorts of automation devices. Many of these things have also helped to improve the end-product, but this was not the prime aim. Next there are inventions, adaptations, and techniques whose main purpose is to extend-directly or indirectly-a supply of raw materials, though often

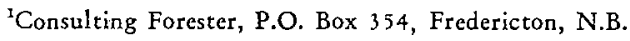


lower production costs followed as a bonus. The development of semichemical pulping and the gradual raising of the "recovery" levels in other forms of woodpulp manufacture are cases in point; the increasing use of sawmill by-products for pulping is another. In other wood-using plants new machines or improvements in old ones have as their chief goal a reduction of waste; for example, smaller chucks on veneer lathes, equipment for endjoining short pieces of lumber or edge-joining narrow strips and more precise and less wasteful sawmill machinery. Not the least important aspect of this quest for more balanced use of the basic resource is the welcome extension of uses for species still in little demand, notably for making pulp and particleboard.

Almost every day some new or better wood products enter the market. The electronic industry brings the cost of TV within the reach of the average householder, and, presto! a huge, new cabinet-industry is born. But casualties can occur just as dramatically. Some of you in this room will recall the sudden demise of the wooden automobile frame and the wood-spoke wheel. Sometimes, too, one wood product pushes another out of the market: witness the steady retreat of the wooden box. Now the wooden pallet is used as a portable base for goods packaged in corrugated-paper boxes. However, less striking developments are, in the aggregate, more important. New papers designed to meet the advancing technology of the printing trades are constantly in demand. The packaging of goods daily grows more diversified and more demanding of the specialty paperboards, wrappers, and containers. Similarly, industrial users of all kinds of panel-boards (plywood, fibreboard and particleboard) are always seeking grades and specifications which will better meet the higher standards the ultimate consumer expects.

Superimposed on this progress in the arts and science of production there are new management techniques which often entail a technology of their own. Noteworthy just now are the drive for industrial integration-both horizontal and vertical - and what might perhaps loosely be called the "instrumentation of management"-linear programming, computer techniques, and the mechanization of many management functions.

Clearly an advancing technology is the outgrowth of research. For most of us it is the results of applied research which are the most impressive. This is partly because we can appreciate them better than the findings of pure research and partly because the former are forced upon our attention by the many practical, every-day applications touching the life of each of us. Many of these might be spawned by a single, major break-through in pure research we may never even hear of-let alone understand. It is no wonder that research has been called an essential part of the bloodstream of industry without which industrial anemia can easily set in." In fact, as John A. Zivnuska ${ }^{3}$ said: "the challenge of competition will be the challenge

"RANKIN, J. W. "Research Challenges Corporate Management". Forest Products Journal, Vol. XI, No. 5 (May, 1961) F. 232.

"ZIVNUSKA, JOHN A. "The future of wood in a competitive market". Paper prepared for presentation at the joint meering of the Puget Sound and Columbia River Sections, Society of American Foresters, Longview, Wash. May 4, 1963. 
of research and development combined with effective marketing." Therefore, if we are to make a realistic appraisal of the influence of technology on the use of wood in the next decade or two, we should examine the present trends in research.

Clearly the forest-based industries will benefit from much research and development throughout almost the whole spectrum of science, provided that management seizes its opportunities. But all have equal access to such benefits, so that, by and large, no one industrial sector is likely to gain more than another from the fruits of research originating outside its own group. In other words, the relative and competitive success of a given segment of industry will depend very largely on its own research effort.

It is difficult to evaluate research programs since they cannot be measured in dollars alone; yet there is perhaps no better yardstick of comparison. It is therefore revealing to look at what various industries are investing in research.

Data on Canadian spending in forest-products research are sketchy, but it was probably less than $\$ 3,000,000$ in 1960 and fewer than 200 professional workers seem to have been so engaged. This sum is little more than one-tenth of one per cent of the net value of our forest production. While such a small investment in the future welfare of these industries is hard to justify, it must be admitted that the Canadian effort could, at best, be only a fraction of what the corresponding United States outlay should be.

The overall expenditure on industrial research and development in the United States in 1960 was roughly 4.5 per cent of the net value of sales of the industries concerned, counting only those firms which reported some activity in this field. But, on the average, over half the total expenditure is made by outside agencies, chiefly government and universities, although the general picture was distorted by the huge government programs in missiles and electronics. The average investment by industry itself was about two per cent of net sales. In both the "paper and allied products" and the "lumber, wood products and furniture" groups about 0.6 per cent of net sales was applied to research and development; and of this only a small part came from government. In the same terms, the chemical industries spent over four per cent, rubber products about two per cent, fabricated metal products roughly 1.5 per cent, primary metals almost one per cent, and textiles about the same as lumber and wood products. As for the numbers of workers engaged in research and development, the paper and lumber groups were at the bottom of the list of major industries with around 2,500 such workers beween them-which was substantially fewer than any of the other groups just mentioned. In fact, in the lumber and woodworking industries only about four workers in every 1,0a0 were so engaged. ${ }^{4}$ Although I have no figures to substantiate the assertion, it is reported that industry in Europe, including the forest-based industries, supports much greater research and development programs.

s"Research and development in industry, 1960". National Science Foundation, Washington, D.C. 
All the figures just quoted relate to applied research and commercial development only. A well rounded program should allot from five to ten per cent of the total research appropriation to pure research. The indications are that no such expenditures are being made on basic research in wood.

From the foregoing facts, it seems fair to conclude that the forest-based industries are not keeping pace with the research effort of their competitors and potential competitors. This bodes ill for the future. Consider just one major research problem, namely, a comprehensive study of lignin. Tens of thousands of tons of this substance are burned or flushed down mill sewers every day by the chemical-pulp industry of the world. Yet many believe that lignin could become an extremely versatile raw material.

Despite the great significance of research in raising the level of wood utilization, it is not all-important. A weakness in technological progress will show up most quickly in highly sophisticated and relatively affluent markets where there is intense rivalry for the consumers' favour. But, by sheer weight of numbers, the peoples of the so-called "emerging" nations constitute a huge potential market for things which we regard as the simplest necessities of life. The first impact of technology in those nations is on increased productivity in general by such means as the development of electric energy, irrigation, improved agriculture, better storage of food, the more efficient use of local materials (including wood), and the discovery and exploitation of untapped native resources.

As we already know, this can touch off a steady rise in the standards of living and literacy. But it will be some time before many of these impoverished peoples can afford the wide choice of consumer goods we enjoy. They will probably progress through much the same stages as our great-grandfathers, grandfathers, and fathers did; at what pace they do so may depend upon the rate of growth of their gross national incomes in relation to the growth of their populations. In any event, the first stage will be to satisfy the demand for such things as will bring the greatest betterment in their lot at lowest cost-do-it-yourself materials, cheap printing papers and so forth.

One way of gauging the impact of technology on the use of wood as it has affected us here in North America is by noting certain significant trends during the past few decades. The following very rough statistical comparisons are based on the increases in the averages of the relevant figures for the fouryear period of 1956-59 (inclusive) over the corresponding averages for the base period of 1926-29 (inclusive). (As a multiplier of the 1926-29 value)

Population of Canada

Population of the World

Canadian production of industrial wood*

" production of lumber

" exports of lumber

" production of woodpulp exports of woodpulp

Net value of all Canadian forest products ( $x$ 5-1/8)

divided by the general wholesale price index $(x 1-7 / 8)$

Increase

$\mathrm{x} 1-3 / 4(+)$

x $1-3 / 7$

$\mathrm{x} 1-4 / 5(+)$

$\mathrm{x} 1-2 / 3(+)$

x $1-9 / 10$

$\times 2$

(+)

x $2-3 / 5(+)$

* All uses other than for fuel and charcoal.

$\times 2-3 / 4(-)$ 
The Canadian plywood industry was in its infancy in the late 1920 's and the particleboard industry was not born until after World War II. Both are now vigorous young giants.

These comparisons show that we are using our forest resources more efficiently than we used to do-at least in an economic sense, but that the rate of increase in our total industrial consumption of wood barely exceeds the rate of growth of the Canadian population-an increase of 1.25 per cent in the per capita output of industrial wood in thirty years. The trend in the United States has been similar, but in some respects more pronounced. The per capita consumption of industrial wood there has declined about 15 per cent in roughly the same period, and the United States production of lumber is lower now than it was 45 years ago.

By way of comparison, the annual Canadian imports of bauxite for our aluminum industry increased during the same period by more than seven times, cement production has more than tripled, shipments of gypsum increased by four and two-fifths times, copper and nickel shipments were up more than four times, and asbestos shipments rose more than three and one-half times. Steel production in Canada has more than tripled since 1946.

It is my belief, therefore, that the total impact of technology in industrialized countries-Canada included-is now placing wood-based products in general at an increasing disadvantage. In some cases this is showing up as a decreasing per caput consumption, in others as a slower rate of increasing consumption than necessary. The severity, and possibly even the direction, of this trend might be altered by much more vigorous programs of research and development. In short, the wood-based industries are weak in their own indigenous technological advance.

In the non-industrialized world the outlook is less clear. If the impact of technology brings a rise in real personal incomes, there should be a noticeable increase in the per caput use of wood in many of its forms. If, on the other hand, the modern technologies act chiefly as a spur to population increases, there could be an absolute increase in wood consumption without a "per caput" rise, and the demand would be chiefly for the cheapest goods.

As for Canada's wood-based industries, their contribution towards more intensive use of wood by the average consumer in the world is not likely to be conspicuous. Their best prospects for expansion lie in a more extensive use of wood products encouraged by a more efficient technology of production resulting in lower cost and even in that direction we have a hard row to hoe. It is well to remember that one of the first actions of the emerging countries is to exploit more effectively their own timber resources. It comes as a shock to realize that the continent of Asia produced 3,157,000 tons of woodpulp in 1956 and $5,871,000$ tons only five years later; this is almost an exact parallel of the growth of the Canadian pulp industry in the 20-year period from 1925 to 1945 . In 1961, the output of paper and paper boards in Asia exceeded the Canadian production by a significant margin." Facts such

\footnotetext{
suepulp and Paper International" (1962 Review Number). Vol. 4, No. 9; August 25, 1962.
} 
as these should cause us to re-appraise our own situation. Have we applied a big enough technological impact of our own? Or have we been content, in the main, just to copy or adapt the innovations of others? If, as I fear, the wood-using industries of the world are dropping behind in the technological race, certainly we in Canada are in no position to blame others for this state of affairs."

${ }^{\circ}$ (The following is the substance of ad lib. comments by the author following the presentation of his prepared paper.)

The pessimistic overtones of these comments are only partially intended. The forward sweep of technology in its widest implications will undoubtedly vastly expand the market for woodbased products during the next two decades. The cloud on the horizon is that the wood industries are supplying relatively little impetus of their own. This being so, they are illequipped to choose their own destiny; in the not-too-distant future they may fall victim to more forward-looking competitors. 